\title{
Effects of Endurance Exercise on Mitochondrial Function in Mice
}

\author{
Gun-Soo Han, PhD ${ }^{1)}$, Seon-Rye Kim, $\mathrm{PhD}^{2)^{*}}$ \\ 1) Department of Sports and Leisure Studies, College of Humanity, Daegu University, Republic of \\ Korea \\ 2) College of Pharmacy, Chungnam National University: 99 Daehakro, Daejeon 305-764, Republic of \\ Korea
}

\begin{abstract}
Purpose] The purpose of this study was to investigate the effects of 8 weeks of endurance exercise on the cardiac mitochondrial function of mice. [Subjects] Ten $129 \mathrm{SvJ} / \mathrm{C} 57 \mathrm{BL} 6$ Male mice were used. The mice were randomly divided into an exercise group $(\mathrm{n}=5$; mean $\pm \mathrm{SD}$ weight, $27.4 \pm 1.6 \mathrm{~g})$ and a control $(\mathrm{n}=5$; mean $\pm \mathrm{SD}$ weight, $28.2 \pm 1.1 \mathrm{~g}$ ). The exercise mice ran on a motor driven treadmill 5 days per week for 30 minutes at a speed of $24 \mathrm{~m} / \mathrm{min}$ for 8 weeks. Mitochondrial function as measured RCI was compared between the exercise and control group mice using an independent $\mathrm{t}$ test. [Results] The exercise mice had a significantly greater state 4 respiration than to the sedentary control mice. There was also a significant difference in RCI between exercise and sedentary control mice. [Conclusion] Endurance exercise decreased RCI, indicating an uncoupling of respiration and oxidative phosphorylation.

Key words: Cardiac hypertrophy, Endurance exercise, Treadmill
\end{abstract}

(This article was submitted Apr. 8, 2013, and was accepted May 29, 2013)

\section{INTRODUCTION}

Mitochondria are the primary site of adenosine triphosphate (ATP) synthesis in cells. There are several factors affecting the mithochondrial function, including nitric oxide, oxidative stress, and ADP and phosphates availability ${ }^{1)}$. The mitochondrial function can be measured by state 3 respiration (oxygen consumption stimulated by ADP), state 4 respiration (oxygen consumption after completion of adenosine diphosphate (ADP) phosphorylation), the ADP:O ratio and the respiratory control index ( $\mathrm{RCI})$. $\mathrm{RCI}$ provides an index of mitochondria coupling ${ }^{2}$. Impaired mitochondrial function results in a decreased RCI, indicative of an uncoupling of respiration and oxidative phosphorylation, and therefore a lower rate of ATP production. A reduction in RCI is associated with reduced cardiac efficiency, which leads to cardiac dysfunction ${ }^{3}$. The relationship between mitochondrial function and exercise training has been examined in several studies. A study by Venditti and $\mathrm{Di} \mathrm{Meo}^{4}$ compared mitochondrial respiratory control of the heart between trained and untrained rats. They found no significant difference in RCI between the groups, as measured by the ratio of state 3 respiration to state 4 respiration. In a human study by Tonkonogi, Walsh, Svensson, and Sahlin ${ }^{5)}$, state 3 respiration, state 4 respiration, and the RCI were compared between pre- and post-exercise training. Their results show that exercise training increased 3 respiration, but state 4 respiration and the RCI remained the same. The ADP:O

${ }^{*}$ To whom correspondence should be addressed.

E-mail:sjsanj@hanmail.net ratios were normal at both pre- and post-training. However, another study showed an elevation of RCI due to an increase in state 3 respiration and a decrease in state 4 respiration following prolonged exhaustive exercise ${ }^{2)}$. Little is known about the effects of prolonged moderate exercise training on cardiac mitochondrial function. Therefore, in this study we used a novel approach to explore how the cardiac mitochondrial function of male mice is affected by endurance exercise training.

\section{SUBJECTS AND METHODS}

This study used Ten $129 \mathrm{SvJ} / \mathrm{C} 57 \mathrm{BL} 6$ Male mice. The mice were randomly allocated to an exercise group $(n=5$; mean \pm SD weight, $27.4 \pm 1.6 \mathrm{~g})$ and a control group $(\mathrm{n}=5$; mean \pm SD weight, $28.2 \pm 1.1 \mathrm{~g}$ ). The exercise group ran on a motor driven treadmill 5 days per week for 30 minutes at a speed of $24 \mathrm{~m} \cdot \mathrm{min}^{-1}$ for 8 weeks. The control group mice were left sedentary for the entire eight weeks after which they were forced to perform an exhaustive bout of exercise. The mice were housed five animals per cage with a light-dark cycle of twelve-hours and had access to laboratory rodent chow and ad libitum. Before the training, all animals were allowed a minimum 1-week familiarization period, exercising for $15 \mathrm{~min}$ a day at $10 \mathrm{~m} / \mathrm{min}$. During the final week of the study, the mice were randomly selected for single bouts of exhaustive exercise. When mouse was unable to keep up with the treadmill, the exercise session was terminated. All experiments were approved by the Institutional Animal Care and Use Committee of the University of Arkansas.

A procedure was used for the subsarcolemmal mito- 
Table 1. Mitochondrial respiration rates, respiratory control index, and ADP:O ratio in mice

\begin{tabular}{lllll}
\hline Group & \multicolumn{1}{c}{ State 3} & State 4 & RCI & ADP:O \\
\hline Exercise & $224.1 \pm 128.4$ & $61.8 \pm 16.5^{\mathrm{A}}$ & $4.9 \pm 3.7^{\mathrm{B}}$ & $1.7 \pm 0.8$ \\
Control & $197.6 \pm 41.3$ & $28.8 \pm 6.6$ & $7.5 \pm 2.0$ & $1.2 \pm 0.3$ \\
\hline
\end{tabular}

Values are mean \pm SE. Unit: $\mathrm{nmol} / \mathrm{min} / \mathrm{mg}$. AB Significantly different $(\mathrm{p}<0.05)$ from the sedentary control mice.

chondria $^{6}$. After anesthesia by an intraperoneal injection of sodium pentobarbital $\left(40 \mathrm{mg} / \mathrm{kg}^{-1}\right)$, hearts were rapidly removed and rinsed in ice-cold buffer containing $225 \mathrm{mM}$ mannitol, $75 \mathrm{mM}$ sucrose, $10 \mathrm{mM}$ MOPS, $10 \mathrm{mM}$ Tris HCL and $1 \mathrm{mM}$ EGTA at $\mathrm{pH} 7.2$ (Buffer I). The heart was minced on ice and placed in a test tube to be weighed. The hearts were homogenized in the buffer using a Tekmar ${ }^{\mathrm{TM}}$ (Cincinnati, OH, USA) homogenizer for 5 seconds. The homogenate was centrifuged for 10 minutes at $550 \times \mathrm{g}$ at $4{ }^{\circ} \mathrm{C}$ in a Beckman-Coulter Allegra ${ }^{\circledR} \mathrm{X}-22$ (Fullerton, CA, USA) high speed centrifuge. The supernatant was centrifuged at $8,800 \times \mathrm{g}$ for $10 \mathrm{~min}$. The resulting pellet was washed with $1 \mathrm{~mL}$ of buffer and resuspended in a buffer containing $250 \mathrm{mM}$ sucrose and $3 \mathrm{mM}$ Tris HCL at $\mathrm{pH} 7.2$ (Buffer II). Then, $2.6 \mathrm{~mL}$ of air- saturated reaction mixture containing $120 \mathrm{mM} \mathrm{KCL}, 10 \mathrm{mM} \mathrm{NaCl}, 2 \mathrm{mM} \mathrm{MgCl}_{2}, 2 \mathrm{mM} \mathrm{KH}_{2} \mathrm{PO}_{4}$, $20 \mathrm{mM}$ MOPS, $0.7 \mathrm{mM} \mathrm{CaCl}_{2}, 1 \mathrm{mM}$ EGTA, $40 \mu \mathrm{M}$ palmitoyl ${ }_{\mathrm{L}}$-carnitine, $1 \mathrm{mM}$ malate and $0.2 \% \mathrm{BSA}$ at $\mathrm{pH} 7.2$ was placed into the sample chamber and allowed to equilibrate for 3 minutes. When the oxygen monitor displayed $100.0 \%$ saturation, $0.4 \mathrm{~mL}$ of sample was placed in the chamber through the slot in the overflow groove. The initial percentage of saturation was recorded each minute for 5 minutes. The final percent saturation was recorded at the end of the 5-minute period. At the same time, $0.2 \mathrm{~mL}$ of ADP was added through the slot in the overflow groove. The change in oxygen saturation was observed over 5 minutes, and the saturation percent was recorded every minute. The drift was recorded until the saturation was steady. The total recording time was 15 to 20 minutes. State 3 respiration, state 4 respiration, $\mathrm{RCI}$, and $\mathrm{ADP}: \mathrm{O}$ ratio were then determined. The independent t-test was used to compare the outcome values between the exercise and control groups. All data are presented as means \pm SE. The independent t-test was used to compare the difference in cardiac mitochondrial function between groups. Values of $p \leq 0.05$ Values of statistically significant. Statistical analysis was conducted using StatView, Version5.0.

\section{RESULTS}

Table 1 displays the results for mitochondrial function. The exercise mice had a significantly greater state respiration than the sedentary control mice. There was also a significant difference in RCI the between exercise and sedentary control mice $(\mathrm{p}<0.05)$.

\section{DISCUSSION}

Cardiac mitochondria are the principal site of ATP production used to maintain a specific energy requirement dur- ing endurance exercise and fasting. The control of oxygen consumption by phosphorylation is measured by the RCI, which indicates the tightness of coupling between respiration and phosphorylation. It is crucial for cells to have a higher RCI because this represents strong or normal mitochondrial respiratory function ${ }^{7}$. In this study, the exercise mice had lower RCI than the sedentary control mice due to an increase in state 4 respiration, indicating mitochondrial uncoupling. It has been suggested that low RCI in exercise mice might be due to mitochondrial damage. The reason for this has not been fully explained, but a study proposed that cardiac mitochondrial functions may be impaired resulting in significant metabolic effects on lipid metabolism ${ }^{8)}$. The results of that study indicate that care should be taken before assigning overweight adults an exercise program to avoid any side effects from this type of exercise.

In the present study, the ADP:O ration did not differ between the groups. This result is consistent with the results of a study which reported that the difference in the ADP:O ratio between trained and untrained was not statistically significant ${ }^{9)}$. However, the trained rats had a slightly higher mean ADP:O ratio. In the present study, the mean value of the ADP:O ratio of the exercise mice was higher than that of the control group mice. The training also increased the value of the ADP:O ratio compared to the sedentary control mice. However, both groups had a near normal ADP:O ratio, which is between 1.5 and 3.0. This result is consistent with the results of Lee, Gu, Xiong, Mitchell, and Emster ${ }^{10)}$. Future studies are needed to investigate short-term and different exercise intensity effects on cardiac mitochondrial function. In conclusion, this study showed eight weeks of endurance exercise may cause an abnormal cardiac mitochondrial function, but did not affect the ADP:O ratios of the groups.

\section{REFERENCES}

1) Friederich M, Hansell P, Palm F: Daibetes, oxidative stress, nitric oxide and mitochondrial function. Curr Diabetes Rev, 2009, 5: 120-144. [Medline] [CrossRef]

2) Madsen K, Ertbjerg P, Djurhuus MS, et al.: Calcium content and respiratory control index of skeletal muscle mitochondrial during exercise and recovery. Am J Physiol, 1996, 271: E1044-E1050. [Medline]

3) Boudina $\mathrm{S}$, Sena $\mathrm{S}$, Theobald $\mathrm{H}$, et al.: Mitochondrial energetics in the heart in obesity-related diabetes: direct evidence for increased uncoupled respiration and activation of uncoupling proteins. Diabetes, 2007, 56: 2457-2466. [Medline] [CrossRef]

4) Venditti P, Di Meo S: Antioxidants, tissue damage, and endurance in trained and untrained young male rats. Arch Biochem Biophys, 1996, 331: 63-68. [Medline] [CrossRef]

5) Tonkonogi M, Walsh B, Svensson M, et al.: Mitochondrial function and antioxidative defense in human muscle: effects of endurance training and oxidative stress. J Physiol, 2000, 528: 379-388. [Medline] [CrossRef]

6) Makazan Z, Saini HK, Dhalla NS: Role of oxidative stress in alternations of mitochondrial function in ischemic-reperfused hearts. Am J Physiol 
Heart Circ Physiol, 2007, 292: 1986-1994. [CrossRef]

7) Fernström M, Tonkonogi M, Sahlin K: Effects of acute and chronic endurance exercise on mitochondrial uncoupling in human skeletal muscle. J Physiol, 2004, 554: 755-763. [Medline] [CrossRef]

8) Cox KB, Liu J, Tian L, et al.: Cardiac hypertrophy in mice with long-chain acyl-CoA dehydrogenase or very long-chain acyl-CoA dehydrogenase deficiency. Lab Invest, 2009, 89: 1348-1354. [Medline] [CrossRef]
9) Bo H, Jiang N, Ma G, et al.: Regulation of mitochondrial uncoupling respiration during exercise in rat hearts: role of reactive oxygen species (ROS) and uncoupling protein 2. Free Radic Biol Med, 2008, 44: 1373-1381. [Medline] [CrossRef]

10) Lee $\mathrm{CP}, \mathrm{Gu} \mathrm{Q}$, Xiong $\mathrm{Y}$, et al.: $\mathrm{P} / \mathrm{O}$ ratios reassessed: Mitochondrial $\mathrm{P} / \mathrm{O}$ ratios consistently exceed 1.5 with succinate and 2.5 with NAD-linked substrates. Fed Am Soc Exp Biol, 1996, 10: 345-350. [Medline] 